\title{
Improving Health Systems: Influence of Technical Capacities of Community Health Volunteers on Use of Community Health Information Systems in Kenya
}

\author{
Susan Njoki Mambo \\ Department of Health \\ Systems Management, \\ Kenya Methodist \\ University, P. O. Box 267, \\ Meru, Kenya
}

\author{
George W. \\ Odhiambo-Otieno \\ Department of Health \\ Sciences, Rongo \\ University, P. O. Box 103 \\ - 40404 , Rongo, Kenya
}

\author{
George Ochieng'- \\ Otieno \\ Department of Health \\ Informatics and \\ Information Systems, \\ Box 43844-00100, \\ Nairobi, Kenya.
}

Kenyatta University, P. O. University, P. O. Box 267 ,

\author{
Wanja Mwaura- \\ Tenermbergen \\ Department of Health \\ Systems Management, \\ Kenya Methodist \\ Meru, Kenya.
}

\begin{abstract}
WHO identified six key pillars of an effective health system namely: leadership and governance; service delivery; health workforce; health information systems; medical products, vaccines and technologies and healthcare financing. This study focused on Community-based Health Management Information System (CbHMIS) of health information pillar. A Community-based Health Management Information System (CbHMIS) is a type of health information system based in the rural community and informal settlements of urban areas. CbHMIS's main objective among others is to produce relevant and quality information to support decision making on public health issues at the community level. The importance of effective information use is still a key impediment to achievement of goals at level one of health care delivery. According to a situation analysis on the state of Community Health Services in year 2014, the functionality of CbHMIS was said to be at $64 \%$ which came down considerably to $55 \%$ in year 2015 documented by USAID, and that access to quality data was not guaranteed through the current CbHMIS.Lack of technical capacities among the CHVs is a serious gap in achievement of information use in Kenya.This study aimed at establishing the factors influencing technical capacities of community health volunteers on use of CbHMIS in Kenya.Other objectives of this study were: To establish the influence of System Availability on CbHMIS use; to find out effects of availability of skills to CHVs on CbHMIS use, To assess the influence of personnel knowledge on CbHMIS use, To identify competencies of CHVs that influence CbHMIS use. The selected counties were Kiambu, Kajiado and Nairobi which gave a rural, urban and peri-urban representation respectively of the country. This was a crosssectional analytical study design, with both quantitative and qualitative data collection methods. The target population was 156 active Community Units (CUs) from the 3 counties where a total sample of $122 \mathrm{CUs}$ (50 in Kiambu; 26 from Kajiado and 46 from Nairobi CUs) was derived using Mugenda and Mugenda formula of populations less than 10,000. Multistage sampling was used to identify the CUs; Systematic random sampling was used to identify total of 366 respondents 3Community Health Volunteers (CHVs) were purposively sampled form each $\mathrm{CU}$ to make a total of 366 (150 in Kiambu; 78 from Kajiado and 138 from Nairobi. A total of 6 KIIs (two from each county) and 3 FGDs (one from each county) were conducted for qualitative data. Interviewer administered questionnaires were used to collect quantitative data, observation checklist was also used. Quantitative data
\end{abstract}

was analyzed using SPSS to generate univariate and bivariate analysis at $\mathrm{p}<0.05$ significance level. Qualitative data was analyzed using content analysis based on key themes generated from the objectives. Results were presented in form of graphs, tables, figures, and narration. Use of Cb-HMIS stood at $56.6 \%$. Slightly above half $51 \%$ of respondents agreed to having technical skills on CbHMIS, However a KII noted that "....We have challenges in training all our CHVS and refresher trainings due to funding so you will find some have been partially trained....". There was statistical significant differences between group means $(\mathrm{F}(2,363)=$ $32.47, \mathrm{p}=.000)$. $\left(\mathrm{X}_{1}\right)$ explains $28.6 \%$ of the total variations in the use of CbHMIS $\left(\mathrm{R}^{2}=.286\right)$. This implies that the use of CBHMIS by Community Units (CU) improves significantly when the CU personnel have better technical capacities.

\section{Keywords}

Health Systems Strengthening, Community Based - Health Management Information system, Use of CBHMIS, Technical capacity factors.

\section{General Terms}

Health Systems Manangement; Technical capacity factors; Community based health management information syatems

\section{INTRODUCTION}

Health systems strengthening (HSS) has become a top priority of many global and national health agendas as a way to improve health outcomes. With the global health context becoming increasingly complex, national health systems are beginning to move away from a focus on disease-specific health responses to comprehensive strengthening of health systems. The global community agrees that without a systems approach, population health outcomes will not further improve (Nutley, 2012). Globally, there has been the need to strengthen country health information systems and information constituencies taking into account that good information is the overriding factor of all pillars of a health system (Cheburet \& Odhiambo-Otieno, 2016a).

In Sub Saharan Africa, there is the recognition of the importance of health information systems to be capable of generating reliable data and information (WHO, 2010). In many countries, health sector reform and decentralization have brought about shifts in functions between the central and peripheral levels and have generated new information needs with changing requirements for data collection, processing, analysis and information dissemination (WHO, 2010). 
Kenya currently runs its District Health Information System DHIS2 which came into force in 2009 , it is an open-source software that has so far showed much promise in improving the functionality of the HMIS systems used in the country (Karuri, Waiganjo, Daniel, \& Manya, 2014). However, not all challenges have been able to be addressed by the HIS and also not all the districts had a health information system, and those that had them were donor funded, and were implemented by non-governmental organizations e.g AMREF,(OdhiamboOtieno \& Odero, 2005) The development of comprehensive community based health information systems is increasingly becoming important for measuring and improving the quality of health services (Jeremie et al., 2014). In Kenya for instance, the DHIS2 did not give emphasis on CBHMIS. However, community involvement component in HMIS in Kenya has been growing which has been accelerated by initiation of community strategy (Karuri et al., 2014). This however, has not reached a level where communities take charge and make decisions on their health issues through the data that they collect because the practice has been collecting and channeling data to higher levels (MoH Kenya, 2008).

Notably, the level of data demand and utilization of the information generated mostly at level one is undocumented $(\mathrm{MoH}, 2010)$. Most of the data collected at the community level only feeds to the district HMIS and minimal decisions are made at community level and hence the level of utilization of information generated by Cb-HMIS undocumented. The County community units from the selected counties lack the requisite technical capacities to operate its Community-based health management information system; Specifically they are affected by System Availability, Availability of skills both for information technology and for CBHMIS, Personnel knowledge, Competency of CHVs, and achievement of goals which is the key gaps that this study seeks to answer.

System availability: One of the main challenges facing primary healthcare systems in many developing countries is the impact of narrowly focused initiatives that tend to take away personnel from essential services (WHO, 2007). In this case, well-funded programs superimpose their own demands on existing healthcare systems and end up dwarfing critical components of the healthcare system. This problem is common in developing countries that rely extensively on donor-funded programs. Organizational members need knowledge and skills to perform RHIS tasks, and specialized technical know-how/ technology (technical) is required for timely analysis and reporting (Aqil et al., 2009)

Karuri et al.,(2014) classified the personnel needed to operate the DHIS2 platform currently in operation in many parts of Kenya into three groups; system administrators, health workers, and regional decision makers. Under this arrangement, the system administrators handle the technical needs of the system, a role that is well recognized and appreciated in Electronic Health Records circles (LaTour \& Eichenwald, 2002).

The health workers enter data into the system based on their experiences. Health workers who use these systems are drawn from both public and private facilities, and their expertise range from specialized disciplines to other supporting disciplines within the healthcare settings. The regional decision makers use it to make decisions regarding their policy options and any interventions needed, including investment and staffing decisions (Mesquita, 2012).

1.1 Availability of Personnel skills: Survey done in Ghana and Uganda indicated that managers at every level throughout the country are expected to regularly monitor their efforts to implement these policies and make informed decision making to achieve their own goals and targets. However the importance of health information systems have increased for community oriented decision making rather than political and bureaucratic supervision (Abajebel, Jira, \& Beyene, 2011).

The personnel needs for the successful operations of a CbHMIS include the need to clarify the roles played by each group, the collection of relevant data that is usable at the point of collection, and feedback from data aggregation centers. It is clear that personnel play a critical role in the operations of the health management information systems (Amref Kenya, 2014).

1.2 Competency of CHVs: Technical capacity available to an MIS not only means individual capacity to operate and manage the system, but also the availability of a critical mass of trained personnel where there are needed to keep the system running (Pepela \& Odhiambo-Otieno, 2016). In other words, an evaluation of the technical capacity of a CbHMIS must take into account both the quality and quantity of personnel available to run it. Both the technical and nontechnical needs (e.g dedicated personnel) of the system must be addressed fully to experience the full range of benefits. Apart from technical skills, WHO (2007) also recognizes that dedicated personnel are essential for the effective delivery of healthcare services, this in addition to technological systems such as CbHMIS. A study by Kibua et al., (2009) in Kibwezi showed that all HMIS personnel were not adequately trained to use the systems.

1.3 Personnel knowledge: Personnel play a key role in the effectiveness of a HMIS, and are regarded as part of the core component of any HMIS system (Karuri et al., 2014). Pepela and Odhiambo-Otieno, (2016) contends that many community-based personnel involved in data collection and entry activities meant to operationalize the CbHMIS do actually need to use the information that they collect in their day-to-day operations. The information is purely used for management and policy decisions however at higher levels of the system. The system ends up with a lot of duplication and waste because no one works to optimize its operations (Pepela \& Odhiambo-Otieno, 2016). In addition to this, vertical processes are in place to provide information to different decision centers, and no effort is made to harmonize the data collection and dissemination procedures.

The personnel needed to operate a HMIS must be computer literate and they must understand how to carry out specific tasks such as data entry and retrieval in the HMIS (HMN \& WHO, 2008). The policies and procedures used in HMIS develop over time and are the basis for procedures that govern access, frequency of use, authorizations, and response mechanisms. The personnel needs of a CbHMIS relates to the system components needed to make it operable. It is thus of great importance that health service providers are trained in information gathering and analytical techniques to equip them with the knowledge to be able to use available information for the right purpose, and this is the best way to improve health governance at community level. This in-turn allow for efficient use of scarce health resources for maximum benefit to the people who need it most at the grass-root level (Jeremie et al., 2014a).

\section{MATERIALS AND METHODS}

To achieve this, the study utilized a descriptive cross-sectional study design which employed both quantitative and qualitative approaches. Quantitative data was collected using 
questionnaires administered to the respondents. Qualitative data was collected through Focus group discussions (FGDs) and Key Informant Interviews (KIIs). Therefore, this research utilized triangulation of several research designs. This approach had been used by several scholars in the past in similar studies due to its ability to increase validity of the outcomes as well as complementing on the weaknesses of each method (Aqil et al., 2009). The independent variables under investigation were: System Availability, Availability of skills both for information technology and for CBHMIS, Personnel knowledge, Competency of CHVs, and achievement of goals. The Dependent Variable of this study is CBHMIS use.

The study areas were three selected counties; Kiambu , Kajiado and Nairobi. According to the Kenya master community units list, Kiambu county has a total of 79 established community units with 64 CUs that are fully functional (Ministry of Health, 2008).Nairobi county has 140 established CUs with only 59 being fully functional $(\mathrm{MoH}$, 2016). Kajiado County has 56 established CU's with 33 CUs fully functional (Kajiado County, 2013) and (MoH, 2016).
The study population for this study was 156 fully functional CU's from the three selectected Counties. Using Mugenda and Mugenda formula of populations below 10,000, a sample size of 122 functional CUs were selected randomly and 3 Community Health Volunteers were interviewed from each $\mathrm{CU}$ which formed a total sample of $366 \mathrm{CHVs}$ as respondents for this study (see table 1). Three (3) Focus Group Discussion were done on 3 Functional community health committees (CHCs) i.e. one from each county. Six Key informants (Community Health Extention Workers (CHEW) and County Coordinator) were considered i.e. two from each county. Only CHVs who had been trained using the community strategy curriculum and had been in operation for at least one year in the selected counties were selected. Multi stage sampling was used to arrive at a desired sample size. Systematic sampling was used to identify the Community Units and purposive sampling was used to sample the three respondents per Community Unit. Data collection instruments used included; observation checklist, interviewer administered questionnaires, Key Informant guide and Focus group discussion guide

\subsection{Table 1: Sample size determination}

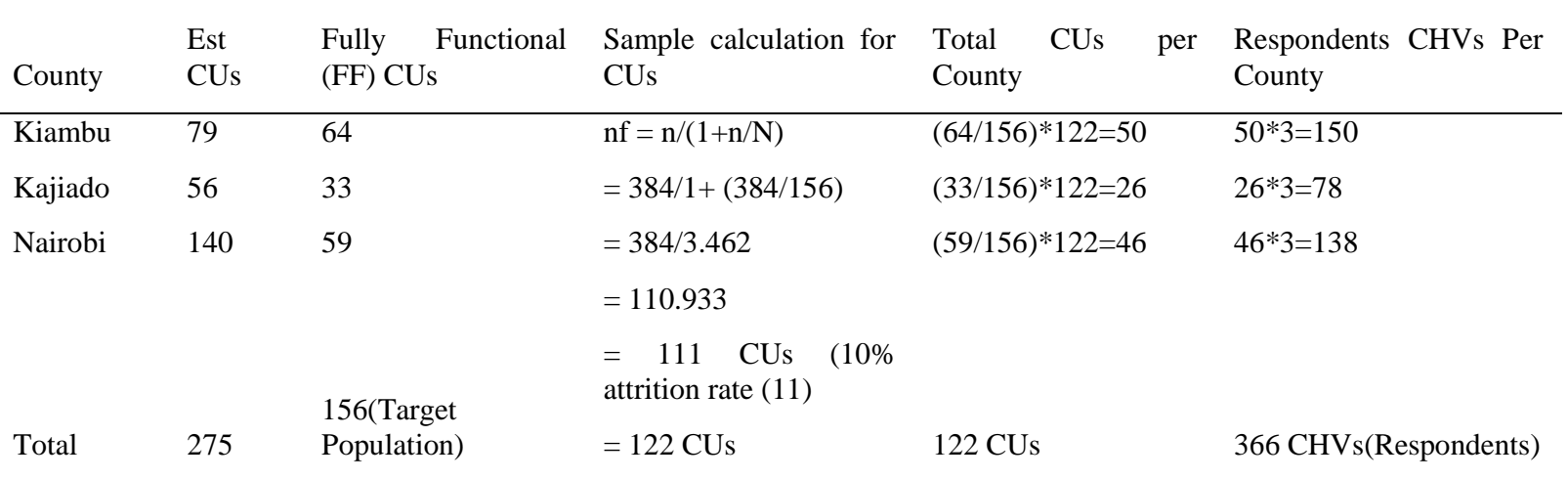

\section{RESULTS}

\subsection{Indicators of Technical capacity of respondents}

On system availability, majority of community units agreed to having an available functional system (composite mean score, 4.00). On Competency of personnel, the respondents agreed that they are conversant with data tools (composite mean score, 3.80). On personnel skills, it is easy for the respondents to collect data (composite mean score, 3.66). When asked about computer literacy understanding of their work to measure availability of skills respondents have knowledge on HMIS (composite mean score, 3.71), and that majority of the respondents (CHVs) in the community units in Kenya said they understand their job well (composite mean score, 4.36). Personnel knowledge, respondents agreed that they have capacity to analyze data in their CU (composite mean score, 3.71) and they also said they have technical knowledge that helps them in achieving their goals (composite mean score, 3.68)

However, on data skills availability, the respondents disagreed with the following: We have trained volunteers who enter data on Management Information system (composite mean score, 3.04 , I am involved in data entry in the computer (composite mean score, 2.39) as shown in table 2

Table 2: Technical capacity indicators

\begin{tabular}{llccc}
\hline Indicator & Construct & $\mathrm{N}$ & Mean & $\begin{array}{l}\text { Std. } \\
\text { Deviation }\end{array}$ \\
\hline System Availability & $\begin{array}{l}\text { We have a functional Health Management Information } \\
\text { system (HMIS) }\end{array}$ & 361 & 4.00 & 0.92 \\
Personnel knowledge & $\begin{array}{l}\text { I have knowledge on Health Management Information } \\
\text { system } \\
\text { Our community Health volunteers (CHV) understand }\end{array}$ & 351 & 4.71 & 1.21 \\
Personnel skills & $\begin{array}{l}\text { their job well } \\
\text { We have trained volunteers who enter data on 361 } \\
\text { Panagement Information system }\end{array}$ & & 3.04 & 0.81 \\
\hline
\end{tabular}




\begin{tabular}{lllll}
\hline Personnel skills & I am involved in data entry in the computer & 356 & 2.39 & 1.28 \\
Competency of CHVs & We are all conversant with the data tools that we use & 358 & 3.80 & 1.11 \\
Personnel knowledge & It is easy for me to collect data & 355 & 3.66 & 1.21 \\
Achievement of goals & $\begin{array}{l}\text { The technical knowledge we have helps us achieve our } \\
\text { objectives in time }\end{array}$ & 359 & 3.68 & 1.08 \\
Personnel Skills & We have capacity to analyze data in our community unit & 360 & 3.71 & 1.13 \\
\hline
\end{tabular}

Slightly above half $51 \%$ of the respondents agreed that they have technical skills on use of CbHMIS in that they have capacity to analyze data in our community unit , and only $7 \%$ of the respondents strongly disagreed as shown in figure 1

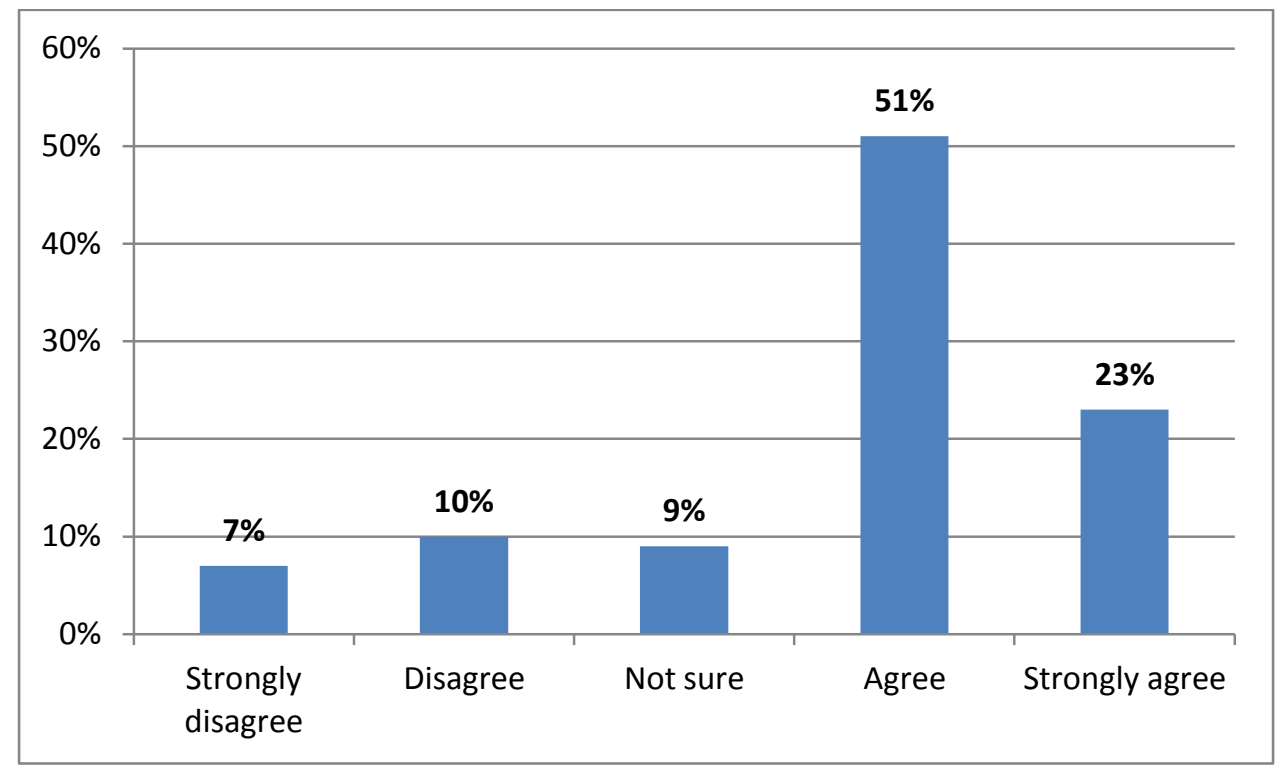

Figure1: Respondents skills of CbHMIS: Capacity to Analyze Data

\subsection{Relationship between Technical Capacity and CbHMIS use}

The Bivariate correlations in Table 3: indicates that there is a positive and significant relationship between the influence of

all technical capacity indicators of Community Units personnel on the use of CbHMIS in Kenya. The influence was stronger between the goals achievement and the overall technical composite $\left(\mathrm{r}=.382, \mathrm{P}=.000\right.$ and $\mathrm{r}=.547^{* *}, \mathrm{P}=$ $.000)$.

Table 3: Relationship between Technical Capacity and CbHMIS use

\begin{tabular}{lllll}
\hline S\# & Indicator & CbHMIS Use & P Value & N \\
\hline 1. & System availability & $.344^{* *}$ & .000 & 366 \\
2. & Skills availability & $.372^{* *}$ & .000 & 366 \\
3. & Personnel Knowledge & $.236^{* *}$ & .000 & 366 \\
4. & Competency of CHVs & $.282^{* *}$ & .000 & 366 \\
5. & Technical composite & $.547^{* *}$ & .000 & 366 \\
\hline
\end{tabular}

\subsection{Comparison of Technical capacity per county}

There was statistical significant differences between group means as determined by one-way ANOVA $(\mathrm{F}(2,363)=32.47$, $\mathrm{p}=.000)$ 
Table 4: comparison of technical capacity factors per county

\begin{tabular}{|c|c|c|c|c|c|c|c|}
\hline \multicolumn{8}{|c|}{ One-Way Analysis of Variance of technical factors by county } \\
\hline & & & $\begin{array}{l}\text { Sum of } \\
\text { Squares }\end{array}$ & df & $\begin{array}{l}\text { Mean } \\
\text { Square }\end{array}$ & $\mathrm{F}$ & Sig. \\
\hline \multirow{3}{*}{ Availability of the system } & \multicolumn{2}{|c|}{ Between Groups (Combined) } & 3.246 & 2 & 1.623 & 1.741 & .177 \\
\hline & \multicolumn{2}{|c|}{ Within Groups } & 338.481 & 363 & .932 & & \\
\hline & \multicolumn{2}{|l|}{ Total } & 341.727 & 365 & & & \\
\hline \multirow[t]{3}{*}{ Availability of skills } & \multicolumn{2}{|c|}{ Between Groups (Combined) } & 33.348 & 2 & 16.674 & 32.003 & .000 \\
\hline & \multicolumn{2}{|c|}{ Within Groups } & 189.128 & 363 & .521 & & \\
\hline & \multicolumn{2}{|l|}{ Total } & 222.475 & 365 & & & \\
\hline \multirow[t]{3}{*}{ CbHMIS skills type } & \multicolumn{2}{|c|}{ Between Groups (Combined) } & 60.950 & 2 & 30.475 & 31.000 & .000 \\
\hline & \multicolumn{2}{|c|}{ Within Groups } & 356.850 & 363 & .983 & & \\
\hline & \multicolumn{2}{|l|}{ Total } & 417.801 & 365 & & & \\
\hline \multirow[t]{3}{*}{ Personnel knowledge } & $\begin{array}{l}\text { Between } \\
\text { Groups }\end{array}$ & (Combined) & 4.097 & 2 & 2.049 & 1.424 & .242 \\
\hline & \multicolumn{2}{|c|}{ Within Groups } & 522.395 & 363 & 1.439 & & \\
\hline & \multicolumn{2}{|l|}{ Total } & 526.492 & 365 & & & \\
\hline \multirow[t]{3}{*}{ Competency of CHVs } & \multicolumn{2}{|c|}{ Between Groups (Combined) } & 12.722 & 2 & 6.361 & 5.320 & .005 \\
\hline & \multicolumn{2}{|c|}{ Within Groups } & 434.013 & 363 & 1.196 & & \\
\hline & \multicolumn{2}{|l|}{ Total } & 446.735 & 365 & & & \\
\hline
\end{tabular}

\subsection{Influence of Technical Capacity on CbHMIS Use: Regression}

All parameters were found to be significant at Pearson correlation level. These findings were subjected to further analysis where a univariate linear regression model $\mathrm{Y}=\beta 0+$ $\beta_{1} X_{1}+\varepsilon$ was used to determine the influence of technical capacity on use of CbHMIS by CUs.

The coefficients in the regression model indicate that technical capacity will always exist at a certain minimum ( $\beta 0$
$=1.670, P<.001)$. This predicts that the attention to technical capacity of community units personnel positively and significantly influences the use of CbHMIS $(\beta 1=.476, P=$ $.001)$. The study further revealed that technical capacity of CU personnel (X1) explains $28.6 \%$ of the total variations in the use of CbHMIS $\left(\mathrm{R}^{2}=.286\right)$. This confirms the findings of the bivariate correlations which indicated that when the technical capacity of the CU personnel improves, the use of CbHMIS will also improve as indicated in table 5

Table5: Model Summary for technical capacity: Regression

\begin{tabular}{|c|c|c|c|}
\hline & B & SE B & $\mathbf{B}$ \\
\hline \multicolumn{4}{|l|}{ Step 1} \\
\hline Constant & 1.670 & .165 & \\
\hline Technical Capacity & .526 & .045 & .526 \\
\hline \multicolumn{4}{|l|}{ Step 2} \\
\hline (Constant) & 1.223 & .169 & \\
\hline Technical capacity & .381 & .048 & .476 \\
\hline Availability of the system & .017 & .029 & .123 \\
\hline \multicolumn{4}{|c|}{$\begin{array}{l}\text { Note: } \mathbf{R}^{2}=.286 \text { for Step } 1, \Delta \mathbf{R}^{2}=.280 \text { for Step } 2(\mathbf{p}=. \mathbf{0 0 0}), * \mathbf{p}<.000 \\
\text { a. Dependent Variable: CbHMIS use }\end{array}$} \\
\hline
\end{tabular}




\section{DISCUSSION}

\subsection{Technical Capacity of Community Units Personnel and Use of CbHMIS}

A superior and strong technical capacity is an important dynamic capability required to drive superior performance in organizations operating in a dynamic environment that characterizes organizations today. The findings of this study agree with Pepela and Odhiambo-Otieno that most of the information systems were still manual and data could not be shared easily for evidence based-decision making (OdhiamboOtieno, 2005b; Pepela \& Odhiambo-Otieno, 2016). Further, the results agree with Berkman et al. (2004) in his study on literacy and health outcomes that disparities in access to health information, service utilization and technology would result in lower usage rates of preventive services, less knowledge of chronic diseases, management and poorer reported health status as echoed by community units (Berkman et al., 2004).

Community-based systems will play an even bigger role as we move from an era of health system strengthening to an era of universal health coverage (UHC) (Lenette, 2014). From the previous literature search, it is evident that in developing countries, CbHMIS are not well equipped and utilized to support the entire health system. It is also clear that empowerment of community health volunteers through equipping them with technical; capacity is key in ensuring the service provision at level one is optimally delivered through informed decision making.

The results of both bivariate correlations $(\mathrm{r}=.538 * *, P=.001)$ and univariate regression analysis $(\beta 1=.476, P=.001)$ indicates that technical capacity of $\mathrm{CU}$ personnel have a positive and significant influence on the use of CbHMIS by community units in Kenya. This means that the more equipped community units personnel are with technical capacities, the better the use of CbHMIS.

It is evident that majority of the respondents (CHVs) in the community units in Kenya have the technical skills in that they understand their job well.

The results showed availability of a functional HMIS system which is critical in advancing the use of information. This results agrees with the results by Nadia, that majority of the community units reviewed have a functional HMIS however, it utilized manual systems processes and results could not be shared easily for evidence-based decision-making (Nadia, 2011)

The community units personnel are conversant with data tools that they use for data collection and that it is easy for the respondents to collect data as indicated in this study, The study also found that the tools used were standardized, that they were also standard across all community units, and specific to each area of service e.g TB, HIV/AIDs etc. On the contrary, Odhiambo-Otieno's study however notes that proliferation of many different tools for reporting existed and were barriers for reporting (Odhiambo-Otieno, 2005b).

This study revealed that CbHMIS personnel knowledge on HMIS is critical. This finding concurs with observations and conclusions made by earlier scholars in implementation of community strategy (which is a programme that ensures community health volunteers are well equipped with technical capacities) in Nyanza that well-coordinated actions across sectors at the community level would increase efficiency in improving health outcomes and "AfyaYetu, JukumuLetu" (MOPHS, 2013).

A comparative analysis of the past studies indicated that the findings of the current study are consistent with the works of several scholars who attempted to find out influence and importance of the capacity to analyze data generated by the community units is very important and technical knowledge that the community units personnel are given is very important in helping them achieve their goals.

The study findings indicated that presence of volunteers who are equipped with data entry skills is important and critical for the general functioning of the CbHMIS. However, an FGD respondent noted that, ' '...We never receive refresher training to remind us on how to go about our data management hence we are likely to continue doing things without ability to interrogate them ...similarly, some members who may join the community units late always take time to be trained...'

\section{CONCLUSIONS AND RECOMMENDATIONS}

Community-based HMIS will play an even bigger role as we move from an era of health system strengthening to an era of universal health coverage (UHC) (Lenette, 2014).

From the study results, for CbHMIS use to improve, attention needs to be given to enhancing personnel knowledge which indicated strong significance but with the least corelation and hence it is paramount. Secondly, competency of CHVs who are the people who implement the CbHMIS needs to be improved through training and refresher trainings. Availability of system for use by the CHVs is very key and despite its availability to the CUs who participated in the study, its state of being manual is still a limiting factor and hence provision of a blended system or electronic system will be an enabler to improving CbHMIS use in Kenya. Inadequacy of training given to the community health volunteers on the use of CBHMIS has significantly influenced negatively its use. There is need for refresher courses offered to the trained CVHs on their capacities for CBHMIS use.

This study recommends that the community units should build more and stronger capacities in technical skills of their community health volunteers. Similarly, the manual data collection and reporting tools is bulky and sometimes limiting in collection of timely data and its analysis due to stock-outs.

The government through the counties should provide for an electronic system of CBHMIS as this will help the community units to swiftly relay the data to higher level, and ensure timely collection and analysis of data including timely decision making.

\section{ACKNOWLEDGMENTS}

The process of synthesizing this thesis was undertaken with substantial input from various people whom I would like to acknowledge: First I wish to thank the Lord God for giving me the strength to press on even when the going got tough. Special gratitude goes to my supervisors Prof. George W Odhiambo-Otieno and Dr. George Ochieng' Otieno for keeping me focused and on track, for their input, encouragement, support and availability for consultation. I also want to appreciate the Chair of Department, Dr. Wanja Mwaura-Tenambergen. To Dr. Kihara Peter and Mr. Solomon Cheboi, your great input in this work where many statistics were involved, you helped me make sense of every digit, I do appreciate your great insight and guidance. All other lecturers from the Department of Health Systems Management for 
offering me advice and encouragement whenever I needed it, please receive my appreciation. I thank the health system leadership for Kiambu, Nairobi and Kajiado Counties, and the Sub-County heads who have made the writing of this proposal possible. My sincere thanks go to my husband John Phillip Kaguchia and our daughters Tehille and Ngatho for their understanding during the course of study. Finally, I specially thank my colleagues Rosalia Kalani, Susan Njuguna, Eunice Mwangi, Caroline Kawila, Safari Agure and Kagwiria Kioga for their sincere contributions and support throughout this course of study.

God bless you all.

\section{REFERENCES}

[1] Aqil, Anwer, Theo Lippeveld, and Dairiku Hozumi (2009)"PRISM Framework: A Paradigm Shift for Designing, Strengthening and Evaluating Routine Health Information Systems." Health Policy and Planning 24, no. 3 (May 2009): 217-28. https://doi.org/10.1093/heapol/czp010.

[2] Abajebel, S., Jira, C., \& Beyene, W. (2011). Utilization of Health Information System at District Level in Jimma Zone Oromia Regional State, South West Ethiopia. Ethiopian Journal of Health Sciences, 21(Suppl 1), 6576.

[3] Amref Kenya. (2014, June 4). Community Based Health Management Information System (CBHMIS) "Taarifa" Project (Jan-2013 - Dec-2015). Retrieved November 4, 2016, from https://amrfhrtg.wordpress.com/2014/06/04/communitybased-health-management-information-system-cbhmistaarifa-project/

[4] Berkman, N. D., Dewalt, D. A., Pignone, M. P., Sheridan, S. L., Lohr, K. N., Lux, L., ... Bonito, A. J. (2004). Literacy and Health Outcomes: Summary. Agency for Healthcare Research and Quality (US). Retrieved from https://www.ncbi.nlm.nih.gov/books/NBK11942/

[5] Cheburet, Samuel, and G.W Odhiambo-Otieno. (2016) "Process Factors Influencing Data Quality," 2016a. http://journalissues.org/wp-content/uploads/2016/06/ International Research Journal of Public and Environmental Health Vol.3 (6),pp. 132-139, June 2016.

[6] Cheburet-and-Odhiambo-Otieno.pdf.(2016) "State of Data Quality of Routing Health Management Information System: Case of Uasin Gishu County Referral Hospi Tal, Kenya," 2016 b. http://journalissues.org/wpcontent/uploads/2016/08/Cheburet-and-OdhiamboOtieno.pdf. International Research Journal of Public and Environmental Health Vol.3 (6),pp. 132-139, June 2016.

[7] chewicha, K. (2013)"Community Health Information System for Family-Centered Health Care: Scale-up in Southern Nations, Nationalities and People's Region MEASURE Evaluation.” Publication, 2013. https://www.measureevaluation.org/resources/publicatio ns/ja-13-161.

[8] Jeremie, Nzanzu, Dan Kaseje, Rose Olayo, and Caroline Akinyi.(2014) "Utilization of Community-Based Health Information Systems in Decision Making and Health Action in Nyalenda, Kisumu County, Kenya." Universal Journal of Medical Science 2, no. 4 (2014): 37-42.

[9] Health Metrics Network, \& World Health Organization (Eds.). (2008). Assessing the national health information system: an assessment tool (Version 4.00). Geneva: World Health Organization.
[10] Kaburu, E., Kaburi, L., \& Okero, D. (2016). Factors Influencing the Functionality of Community- Based Health Information Systems in Embakasi Sub- County, Nairobi County, Kenya | Qualitative Research | Quantitative Research. Retrieved March 19, 2018, from https://www.scribd.com/document/315323806/FactorsInfluencing-the-Functionality-of-Community-BasedHealth-Information-Systems-in-Embakasi-Sub-CountyNairobi-County-Kenya

[11] Kibua, T. N., Muia, D. M., \& Keraka, M. (2009). AMREF Discussion Paper Series.

[12] LaTour, K. M., \& Eichenwald, S. (2002). Health Information Management: Concepts, Principles, and Practice. Chicago, Ill: American Health Information Management Associ.

[13] Mesquita, A. (2012). User Perception and Influencing Factors of Technology in Everyday Life (1 edition). Hershey, PA: IGI Global.

[14] Ministry of Health, K. (2008). Collect, Manage, Visualize and Explore your Data. Retrieved November 4, 2016, from https://www.dhis2.org/

[15] Ministry of Health, K. (2010). Microsoft Word Community Strategy Evaluation report October 2010.doc

14_2010_HE_002_Community_Strategy_Evaluation_rep ort_October_2010.pdf. Retrieved November 4, 2016, from

http://www.unicef.org/evaldatabase/files/14_2010_HE_0 02_Community_Strategy_Evaluation_report_October_20 10.pdf

[16] Karuri, Josephine, Peter Waiganjo, ORWA Daniel, and Ayub MANYA.(2014) "DHIS2: The Tool to Improve Health Data Demand and Use in Kenya." Journal of Health Informatics in Developing Countries 8, no. 1 (2014). http://jhidc.org/index.php/jhidc/article/view/113.

[17] Lenette, Golding. "Strengthening_Community_Health_Systems_through_ CHWs_and_mHealth.pdf," 2014. http://www.coregroup.org/storage/documents/Fall_Confe rence_2014/Strengthening_Community_Health_Systems _through_CHWs_and_mHealth.pdf.

[18] Measure, Evaluation. (2009) "Technical Consultation on Information Systems for Community-Based HIV Programs - MEASURE Evaluation," 2009. https://www.measureevaluation.org/our-work/hivaids/community-based-hiv-info-systems/hiv-meetingregistration/folder_contents?show_all=true.

[19] Ministry of Health, Kenya. (2016) "Collect, Manage, Visualize and Explore Your Data," 2008 https://www.dhis2.org/. "Kenya Master Health Facility List: Find All the Health Facilities in Kenya," nd 2016. http://kmhfl.health.go.ke/\#/home."Microsoft Word Community Strategy Evaluation Report October 2010.doc

14_2010_HE_002_Community_Strategy_Evaluation_rep ort_October_2010.pdf," 2010 . http://www.ünicef.org/evaldatabase/files/14_2010_HE_0 02_Community_Strategy_Evaluation_report_October_20 10.pdf.

[20] Nutley, T.(2012) "Improving Data Use in Decision Making: An Intervention to Strengthen Health Systems - MEASURE Evaluation." Publication, 2012 https://www.measureevaluation.org/resources/publicatio $\mathrm{ns} / \mathrm{sr}-12-73$

[21] Odhiambo-Otieno, George W, and Wilson WO Odero.(2005) "Evaluation Criteria for the District Health Management Information Systems: Lessons from the 
Ministry of Health, Kenya." African Health Sciences 5, no. 1 (March 2005): 59-64.

[22] Pepela, Wanjala, and G.W Odhiambo-Otieno.(2016) "Community Health Information System Utility: A Case of Bungoma C Ounty Kenya," 2016. http://journalissues.org/wpcontent/uploads/2016/04/Pepela-and-OdhiamboOtieno.pdf.

[23] Sharma, Reetu, Premila Webster, and Sanghita Bhattacharyya.(2014) "Factors Affecting the Performance of Community Health Workers in India: A Multi-Stakeholder Perspective." Global Health Action 7, no. 0 (October 13, 2014). https://doi.org/10.3402/gha.v7.25352.

[24] World Health Organization.(2010) "WHO_MBHSS 2010 full_web.pdf," http://www.who.int/healthinfo/systems/WHO_MBHSS_ 2010_full_web.pdf.

[25] World Health Organization. (2007). everybodys_business.pdf. Retrieved November 4, 2016, from

http://www.who.int/healthsystems/strategy/everybodys_b usiness.pdf 